QUADERNS DE FILOSOFIA VOL. I NÚM. 2 (20I4): I09-22

ISSN: 234I-I 4I 4

DOI: $10.7203 /$ QFIA.I.2.4I3O

José GAOS

\title{
Prosopopeya del filósofo
}

Segunda sesión [Fondo Uno, Carpeta I 5 bis, Folios 2568a-2568s]

$\mathrm{V}$

IMOS ANTEAYER cómo este tema, PROSOPOPEYA DEL FILOSOFO, esto es, cómo el hablar el filósofo de sí mismo es algo necesario al filósofo, particularmente en la actualidad, y ello es así porque en la actualidad la Filosofía se encuentra en una crisis respecto de sí misma, sobre la cual los pormenores indispensables van a ser dados hoy.

El filósofo necesita preguntarse en qué consiste la Filosofía, esto es, su propio ser, y necesita preguntárselo para saber si ha de perseverar en ese su ser o, por el contrario, debe decirle adiós a la Filosofía.

Empezábamos esta caracterización de la personalidad del filósofo partiendo de las zonas más excéntricas referentes a esta personalidad y, progresivamente, adentrándonos en la intimidad misma de ella. Y empezamos por notar que el filósofo y un poco el intelectual, en general — con las reservas que acerca de la aplicación de este término de intelectual habría que hacer-, empezamos por notar que el filósofo, y el intelectual en general, ha sido, desde siempre, un hombre aparte de los demás, un hombre de vida aparte de la vida colectiva de los demás, un hombre en abstracción, abstraído. Y esto en punto al medio ambiente, al medio en que su existencia transcurre y su actividad se ejerce. Lo es también un poco, un tanto y por lo menos frecuentemente, en cuanto al indumento y hasta el tocado y demás atributos y signos externos de su personalidad. De aquí el tipo abstraído o absorto con que, frecuentemente y no sin veracidad, se le ha pintado. Y es también hombre aparte y que lleva una vida en abstracción de la vida pública, por ejemplo, política, y en abstracción de las zonas interiores de la vida privada, de las cuales prescinde, como el humano trato social, las pasiones, los placeres de los hombres, según los términos del ......... ${ }^{1}$ platónico y de ciertos aspectos de goce de la vida cultural, de ciertas

${ }^{1}$ Reproducimos así las varias líneas de puntos que se encuentran en el texto a máquina, que sin duda indican huecos o palabras ilegibles en la versión taquigráfica. 
zonas de la vida afectiva y, naturalmente, como la abstracción tiene no sólo el sentido negativo de aquello de que se prescinde, sino el sentido positivo de aquello con que uno solo rectifica ${ }^{2}$ después del prescindir, ese hombre hace vida en abstracción de $\mathrm{d}^{3}$ la vida profesional puramente filosófico-técnica, de todas aquellas zonas de la vida privada que son el estrato, siquiera biológico y hasta institucional de su vida profesional.

Y vimos, por último, que esta abstracción tiene, refiriéndonos estrictamente al filósofo, un sentido particular: es aquella abstracción filosófica o absoluta que al final de la primera conferencia procuramos analizar y describir. Particularmente insistíamos en dos puntos: en la descripción del ente, del medio ambiente del filósofo y en la descripción de esta última intimidad de la abstracción radical o absoluta. Y en cuanto al .......... ${ }^{4}$ lo describíamos como la Biblioteca, como ese horizonte de libros en que el libro domina la existencia del ente humano recluso en el recinto de los libros.

Interpretábamos esto, que bien puede llamarse bibliotecracia, interpretábamos esta bibliotecracia como una absorción, una dominación, una sustitución de la vida por su doblez espiritual e intentábamos señalar las causas generativas, posibilitadoras de ese doblez. Por una parte, un residuo de ciertas formas muy primitivas y, por tanto, muy fundamentales, de la existencia humana y del ser del hombre: el ente biológico del doble y, por otro lado, como última condición, la historicidad o temporalidad del hombre.

El modo como el libro se maneja hoy es fundamentalmente un modo dimanante a tomar el libro en un sentido histórico y en general, si existe el libro y si una vida puede ser dominada o sustituida por él, esto es así y sólo puede ser así con referencia a un ente al cual o al ser del cual le es esencial el pasado, el contemplarse en la función de este pasado.

Y en punto a la abstracción filosófica o absoluta como intimidad radical del filósofo, procuramos describirla mostrando en ella un esfuerzo por alcanzar el máximo prescindir, lo que suponía el disponer de un instrumento de enajenación máxima y este instrumento está al alcance del hombre en la razón, en esa zona radical del hombre, que es su individual razón. La razón es la única porción del hombre, la única de sus actividades que tiene el caracter de reflexibilidad, de esa posibilidad de dirección o de doblez que le permite enajenar de sí todo, convirtiéndolo en su objeto, con la sola excepción de sí mismo, instrumento y agente de esta máxima enajenación. La consecuencia

\footnotetext{
${ }^{2}$ Aquí hay seguramente un error. El sentido apunta a aquello por lo que el hombre se deja absorber: lo que motiva su abstracción y queda en pie tras ella; utilizando un término que más tarde utiliza Gaos aquí mismo, aquello en que uno "se recluye"...

${ }^{3}$ Según el modo de expresión típico de Gaos, aquí tendría que leerse "en".

${ }^{4}$ Con muchas probabilidad, aquí debería leerse "medio ambiente".
} 
es que el hombre ha caído en la soledad de su razón y esto es esfuerzo de la enajenación absoluta o de la soledad radical, que se nos presentaba al final de la primera conferencia como un esfuerzo casi demencial y nos descubría la razón o sinrazón - si ustedes quieren - que puede mover a un determinado tipo de hombre a esta enajenación, a esta radical abstracción, que es lo que vamos a intentar exponer hoy.

Pues bien. Desde sus mismos orígenes en Grecia, hace veintiséis siglos, los filósofos han poseído y difundido una doctrina acerca de sí propios y de su filosofía. Han tenido una Filosofía del Filósofo o, si la repetición de palabras no suena desmesuradamente a chin-chin, una Filosofía de la Filosofía. Y esta Filosofía está expresada y resumida en el mismo nombre con que el filósofo la bautizó a sí propia, en ese nombre de Filo-sofía, cuya interpretación es bien conocida de todo el mundo.

Supone, implica dos elementos. Hay un elemento afectivo, hay una filia, una afición, un amor o un nexo; y, por otra parte, hay, como objeto de esta filía, una sofía, un saber. Lo curioso es cómo los griegos han interpretado este saber y por sus orígenes lo han interpretado como un "thaûma", un esfuerzo. Un taumaturgo es el que hace cosas maravillosas o maravillas. Quizá es excesivo, por mi parte, recordarlo.

Y si por sus orígenes es un esfuerzo, por su esencia misma es una teoría, esto es, un ver o un interpretar; pero hasta tal punto hay conjunción entre este ver y contemplar, por una parte, y el afán o afición por él, que cuando el filósofo griego escribe la página suprema de su Historia, que es una de las páginas de la Metafísica de Aristóteles, el filósofo, preso de la enajenación filosófica, escribe "que la teoría es lo más dulce y lo mejor que existe". Y entonces no puede chocarnos que ya desde los primeros filósofos, este afán de saber haya informado la vida entera del filósofo, hasta desalojar de él todas estas zonas en las que hemos dicho que el filósofo vive en la abstracción para recluirse en una vida puramente teorética, esto es, contemplativa.

Ahora bien, esta teoría o doctrina que el filósofo ha tenido siempre acerca de sí mismo y que consiste en que el filósofo ha pasado de sí mismo a los demás hombres, como un hombre movido por ese puro y desinteresado afán de ver y saber cosas, tiene ciertos supuestos que, por una parte, son o implican una Filosofía del saber en general, y, por otra parte, una Filosofía de la realidad.

El saber, en general, se ampara en proposiciones. Estas proposiciones tienen la condición de descubrir la verdadera realidad de las cosas. Lo curioso es que la verdadera realidad de las cosas tiene una cierta unidad y como consecuencia de que la realidad misma verdadera de las cosas tenga una cierta unidad, estas proposiciones que la descubren, deben tener, consecuentemente, 
una cierta unidad. No hay más que una proposición verdadera posible sobre una sola realidad.

A esto podemos reducir esta doctrina acerca del saber y de la realidad que son supuestos por la Filosofía del Filósofo, a que me acabo de referir. Y son supuestos porque el filósofo no se dejaría mover por ese afán, por esa afición de saber, si el saber no le fuese individualmente asequible, lo que supone esta unidad de la realidad y este saber para el individuo capaz de conquistarlo en los términos de su vida.

Lo interesante es que el saber filosófico es una posición eminente del saber en general. Esto es lo interesante. El saber filosófico es el saber principal. No se puede traducir con otras palabras, aquellas con que los griegos mejor lo caracterizaban. El saber filosófico es el saber del principio, el ${ }^{5}$, palabra que tiene que ver con arquí, que es una palabra familiar para quien sabe lo que quiere decir anarquía, autarquía, etcétera. Se trata, pues, del saber del principio, del saber por principio, del saber principal.

Podríamos llamarle también el saber absoluto, con una terminología ${ }^{6}$ más moderna, pero en definitiva, ¿qué clase de saber? Es esto, pues, creo que con el menor número de palabras posible, es este saber filosófico un saber tal que, poseído él, o no es posible ya ningún otro saber o, suponiendo que lo sea, todo saber posible ulterior no sería más que mera consecuencia, mero complemento secundario de ese saber poseído. Y, en segundo lugar, el único saber capaz de amparar una acción práctica, una conducta en la vida: resuelta, unívoca, precisa.

Saber, por otra parte, necesario, si la vida ha de ser regida por la razón, que es otro supuesto de la Filosofía desde sus orígenes.

Ahora bien, para que un saber pueda tener este carácter de definitivo y amparar una conducta con esta resolución, es evidentemente menester que sea asequible al individuo en el transcurso de su vida. De lo contrario, no puede tomar esos caracteres de definitivo y absoluto, a que me acabo de referir. Pero, a su vez, esto no sería posible — repito - si ese saber no tuviera una cierta unidad, si ese saber hubiera de pluralizarse en los saberes de distintos individuos sucesivamente existentes y a su vez esto no sería posible si la realidad fuese plural en vez de ser unitaria.

Esto es lo que la Filosofía ha opinado acerca de sí misma, de sus propios orígenes y con clara expresión a lo largo de su historia, hasta el punto de que la Historia de la Filosofía es una sucesión desconcertante de doctrinas heterogéneas y contradictorias y, sin embargo, yo no sé que ninguna de estas filosofías

${ }^{5}$ Un espacio en blanco, seguramente para la palabra griega "arché".

${ }^{6} \mathrm{El}$ texto que nos sirve de original dice "tecnología". 
haya puesto radicalmente en tela de juicio esta propia interpretación de lo que la Filosofía es. Pero precisamente esa vida en la biblioteca, ese saber histórico que caracteriza la existencia del filósofo contemporáneo y también la madurez de la vida, el proceso de madurez de la vida, lo invalida, lo ha invalidado contemporáneamente. Como esto es confesión, se ha olvidado ${ }^{7}$ en mi propia biografía y yo en esto no me creo sino un caso más, un ejemplo más acerca de mi generación, a la inmediata anterior y a la de nuestros inmediatos discípulos, y digo que han invalidado totalmente esta Filosofía ${ }^{8}$ porque, en primer lugar, ese saber histórico nos ha enseńado que esa idea unitaria de la realidad es un producto del genio griego, es una manera de ver la realidad, que han tenido los griegos. En definitiva esa unidad le viene a la realidad de considerarla o contemplarla bajo una misma especie. Y ver la cosas bajo especies, encontrar en ellas esencias y géneros comunes, es una cosa propia de los griegos, porque los griegos tenían una constitución mental que les llevaba a ver así la realidad.

Pero hay otras culturas y otros hombres sujetos a ellas, para quienes la realidad o, por lo menos, enormes regiones de la realidad, se presenta con un carácter muy distinto, con una catadura muy diversa y, por ejemplo, los modernos filósofos de Europa particularmente han descubierto la realidad histórica, cuya unidad, si la tiene, dista mucho de ser la unidad de una esencia o de un género. Pero en segundo lugar es que este saber histórico y aun la propia experiencia de esas tres generaciones a que me acabo de referir, ha enseñado hasta qué punto es falsa la tesis o postulado de la unidad de la verdad de la Filosofía, porque lo que nos enseña es precisamente esa sucesión desconcertante y contradictoria de sistemas, porque la experiencia de estas generaciones a que me refiero es nada menos que el haber vivido, como última palabra de la expresión de la verdad, tres promociones de filosofías sucesivas.

Cuando yo entré en la Facultad aún cogimos el neokantismo, aún se nos enseńaba una formación en Kant. Pero yo realmente me he formado en la "Fenomenología" de ......... Y cuando después de haber llevado mucho tiempo, muchos años y mucho trabajo de asimilación de la "Fenomenología" y de una cierta visión de la "Humanización" de Scheler" y de las ideas de otros filósofos, nos encontramos aquí con que vienen las novedades de la llamada Filosofía Existencial, que han puesto nuestro mundo filosófico cabeza abajo y a la Filosofía no sé si por zócalo o montera.

${ }^{7}$ En vez de "olvidado", quizá el término usado aquí por Gaos haya sido “invalidado”. Pero quizá harían falta otros ajustes en la frase.

${ }^{8}$ En la transcripción a máquina hay aquí un punto y seguido que obviamente no tiene razón de ser.

${ }^{9}$ En el original se lee "Schiller", lo que es sin duda un error por "Scheler". 
Nosotros hemos vivido, pues - y pocas veces en la Historia de la Filosofía los pensamientos se han sucedido con tal vértigo-, nosotros hemos vivido la historicidad misma de la Filosofía y de la verdad, de la sustitución de una verdad por otra, con pretensiones, cada una de ellas, de unitarias y definitivas.

Pero es mucho más importante, a mi juicio, la invalidación resultante del proceso mismo de la madurez de la vida. En primer lugar, este proceso ha significado la reducción al absurdo de esa existencia en el ensimismamiento ${ }^{10}$ y creo, para mayor brevedad, poder reducir a dos los puntos en los cuales hemos admitido el absurdo de esta existencia. En primer lugar, en que acaba por representar la incomprensión total. En ese recorrer de las cosas a los libros y de los libros a las cosas, se acaba por no comprender nada, porque la comprensión fundamental es la referencia de los libros — que son los dobles-a las cosas -que son los originales- $y$, en segundo lugar, porque en esa dominación del hombre por el libro y por la lectura, y por la lectura en su forma mecánica, a que aludía el otro día, y en la lectura alimentada por esa tendencia a la inercia y a la pereza mental que hay en esa hipertrofia de lectura, se acaba por llegar a la incomprensibilidad absoluta, al agotamiento de la verdadera capacidad creadora, por razones elementalísimas, porque cuando se acaba por no comprender nada y a no ponerse más que ante el horizonte del libro, ¿qué de interesante hay? Pero, además, ¿qué capacidad se puede tener para comprender un libro verdaderamente progresivo, interesante y vital en parangón con los que ya se tienen en la biblioteca? No hay ninguna, no hay ninguna. Nuevos libros son libros sobre libros, y así sucesivamente, indefinidamente.

Para poder escribir un libro cuya composición se justifique como añadiendo algo verdaderamente esencial a los libros anteriores, no es suficiente haber leído todos los libros anteriores. Y mi experiencia me dice que la cultura contemporánea es contraproducente. Lo que hay que hacer es vivir una vida capaz de añadir algo a los libros anteriores.

Pero lo segundo que se reduce al absurdo, por el proceso de madurez de la vida, es toda vida en abstracción, en general. La vida es concreción - como expuse el otro día—, pero es concreción en la plenitud y su plenitud tiene lugar en la madurez. En la juventud la vida puede ser abstracción, puede ser prescindir de las cosas, pero el hombre no está completo. La juventud es la edad de la abstracción y de las persistencias de la no plenitud de la vida humana en todas sus formas y sectores. Y quizá le pasa lo mismo a la senectud, que en este sentido es una involución hacia la vida sobrevivida, que es también la juventud. Y porque la juventud es vida posible y efectiva, vida en abstracción, por eso el

\footnotetext{
${ }^{10}$ El original dice aquí "estacionamiento", palabra mucho menos probable que "ensimismamiento".
} 
joven puede ser más abstraído que el hombre maduro y el joven, efectivamente, es mucho más introvertido que, en general, el hombre maduro, que es mucho más extrovertido, aunque en algunos individuos perdure a lo largo de la vida la introversión hasta la madurez, y en otros, en la adolescencia, ya apunte con vigor la extroversión.

Y porque la juventud vive mucho más fácilmente reclusa en sí misma y atenta a su vida interior, puede ser también la edad de la hipocresía y del ilusionismo, puede ser también la edad del que anda por el mundo con sus ideas y con sus ideales, pero sin esa fuerte necesidad de constatar con la realidad la veracidad que trae consigo la experiencia de la vida en su madurez.

A cambio de todo esto, la juventud tiene una ventaja y es su enorme precocidad. La vida todavía no está consolidada. Se puede ser todo. La experiencia radical de la madurez es la consolidación de la vida, es el cierre de las posibilidades y, por lo mismo, la urgencia de realizar con autenticidad la única posibilidad efectiva del propio ser.

Yo esto lo siento con una particular agudeza que me parece ejemplar y por eso me permito aludir a mí, si ustedes quieren, con ejemplos que yo suelo dar en clase cuando hago este análisis de la vida humana, poniendo ejemplos como éste:

A los veintiún años a mí me hubiera sido posible hacerme vendedor de corbatas en la Puerta del Sol, por ejemplo. Hoy no me sería posible, porque mis colegas y las autoridades, por ser yo quien soy, me lo impedirían. Aun con una conmoción tan terrible como la que actualmente está pasando la vida española, que ha significado para tantos españoles un cambio radical de su modo de existencia, la transmutación de la forma de la vida civil a la vida, por ejemplo, militar, como forma última y definitiva, no me sería factible un cambio en tal sentido, puesto que yo, aunque mi edad todavía no es demasiado avanzada, jamás podré llegar a ser almirante.

Pues bien, como la vida es concreción y concreción en el sentido del proceso de integración de las partes abstractas, carece de sentido. Y es en la madurez de la vida, precisamente, cuando se advierte éste su carecer de sentido. Así, por ejemplo, en el individuo carece de sentido una vida que cultiva partes abstractas de la vida exclusivamente, como, por ejemplo, la especialidad científica, sin sentir la responsabilidad pura, es barbarie, porque es vida sin concreción. $Y$ en la vida colectiva se siente también como lo puramente abstracto ${ }^{11}$ y no integrado en el concreto total, que la vida puede ser algo tan terrible como es,

\footnotetext{
${ }^{11}$ Hemos puesto "abstracto" aunque la transcripción a máquina reza "estricto", que aquí no parece tener razón de ser; pero esta sustitución no es quizá suficiente para darle cabal sentido al pasaje.
} 
por ejemplo hoy, la técnica sin moral. Esa maravillosa técnica que estudia las concreciones abstractas de la vida, esto es, de la moral, puede producir los más dañinos efectos en vez de producirlos benéficos, únicos que pueden darle un sentido positivo y aceptable por el hombre en la totalidad de la vida humana.

Pero todavía más importante que los efectos de la filosofía es la tercera reducción al absurdo del proceso que la madurez de la vida trae consigo. Es la advertencia de que el empeño de conseguir la abstracción radical, la enajenación máxima, la manía o locura suprema de la filosofía, es imposible. Y es imposible, porque ese afán de apoyar sólo sobre sí, de encontrar un estrato radical en el cual el hombre apoye sólo sobre sí, de encontrarse en la soledad absoluta, es imposible, porque hemos definido la vida humana como una expresión, como el máximo rigor de proposición, como convivencia con compañía. Ser hombre solo no es nada. Dicho de otra manera, lo primero que se necesita para que haya un ser humano es que haya dos. No puede haber un ser humano. Un ser humano es reflejo de otro ser humano con quien convive. Aquí se admite ${ }^{12}$ todo el absurdo del empeño filosófico, que es el empeño de un hombre por comprender el sentido mismo de la humanidad, de la vida humana, y que es una pretensión radicalmente inhumana y como tal la debemos tratar.

Imagínense ustedes, pues, cuál es la situación de la Filosofía y la situación del que ha hecho de ella profesión, si no como filósofo como profesor, al producirse en ella esta acumulación de experiencias y de nuevas verdades. Una radical crisis, radical crisis acerca de su propio ser. Y esto mueve entonces a examinar si realmente las razones ${ }^{13}$ de que la Filosofía se ha originado en el mundo son las que del filósofo o de la Filosofía se han dicho desde sus comienzos o no serán otras completamente distintas de las enseñadas por la doctrina tradicional.

Y llevado por este pensamiento y llevado por la fenomenalidad de esta cuestión, es como yo creo, siendo sincero conmigo mismo y obligando a los demás a ser sinceros por debajo de sus propios principios, es como yo creo advertir que el filósofo no ha gozado ni sigue gozando de ese puro y desinteresado afán de saber, sino de un estrato mucho más profundo de ${ }^{14}$ lo humano, lo que voy a tratar de realizar. Pero antes es menester que diga en qué sentido puede rectificarse esa Filosofía de la realidad y esa Filosofía del saber, a que me he referido antes, como supuesto de la doctrina tradicional acerca de la Filosofía misma. Cómo es posible concebir una verdad plural y la verdad unitaria clásica y qué sentido tiene entonces si la verdad es plural y qué corresponde a la verdad. Esto nos va a poner sobre la pista de la verdadera raíz, del verdadero impulso

${ }^{12}$ Quizá mejor: "se advierte".

${ }^{13}$ La transcripción a máquina que nos sirve de original trae aquí "reacciones".

${ }^{14} \mathrm{La}$ transcripción a máquina trae aquí "que". 
generador de la Filosofía. Y permitidme sentirme profesor, aun cuando esto no sea una clase, y poner un ejemplo de los de clase.

Supongamos que se trata de definir la forma de esta mesa, en la que de cuando en cuando, me apoyo. Podemos proceder de dos maneras. Podemos ponernos de acuerdo para prescindir cada uno de nosotros de sí mismo y entonces llegaríamos a hacer una definición unitaria y diríamos: la forma de la superficie de esta mesa es rectangular. Pero la condición de esta proposición, igualmente verdadera para todos en cuanto a esta verdad unitaria, es que hemos practicado en realidad una formidable abstracción, porque la realidad es la clase con todos los sujetos alojados en ella. Y hemos prescindido, por convención, de cada uno de nosotros.

Pero supongamos que, al revés, todos intervenimos personalmente y convenimos no prescindir de cada uno de nosotros, sino incluirnos a nosotros mismos en la proposición; veamos la fórmula y supongamos que se trata de decir cuál es la forma de la mesa, no prescindiendo o extrayendo de nosotros lo que no tenemos en cuenta cada uno de nosotros. Entonces la verdad revertiría en una pluralidad de proposiciones, cada una de las cuales podría estar expresada por el dibujo en que cada uno de ustedes dibujase la forma de la mesa, con el escorzo que corresponde al lugar en que cada uno está sentado.

Pues hablemos generalizando y supongamos que el Universo es la clase, es decir, que la clase se convierte en Universo. El Universo se integra de sujetos que, así como ustedes, están cada uno sentado en una silla y no encima unos de otros, y se distingue también porque son puntos metafísicos distintos.

La verdad unitaria supone una verdad abstracta, ${ }^{15}$ un prescindir de los sujetos para la plena omnimidad, pero si se trata de la verdad total, íntegra o radical y no abstracta, una verdad que versa no sobre la forma de un objeto, en cuanto a prescindir de los objetos, sino una verdad que enuncia el apoyo mismo de la verdad integral, una verdad en la que se incluye a los sujetos mismos, esta verdad se proyectará por su propia esencia, en tantas proposiciones como comprenda la perspectiva que corresponde a la pluralidad del sujeto metafísico situado en puntos distintos.

La verdad unitaria o abstracta ${ }^{16}$ no ha menester de ser comunicada, porque ya de sí, por su propia naturaleza, es la misma para todos. La que ha menester ser comunicada es esta otra verdad que pretende enunciar la totalidad de lo real y que pretende expresar la realidad en su integridad, porque esa se fragmenta en una porción de proposiciones subjetivas. Ésta es la que ha menester ser comunicada.

\footnotetext{
${ }^{15}$ También aquí hemos sustituido por "abstracta” el "estricta” de la transcripción.

${ }^{16}$ Hicimos aquí la misma sustitución señalada en la nota anterior.
} 
Observen ustedes que esta verdad concreta y plural coincide esencialmente con la actitud filosófica, que es retraerse precisamente a esa estricta verdad de cada uno, que es su punto metafísico. Ésta es la verdad que ha de ser comunicada. Y observen ustedes aquí también el contrasentido de la Filosofía, que es un movimiento entre dos tendencias opuestas: retracción hacia el punto más subjetivo y propio de cada personalidad en su lugar metafísico y, por otra parte, proceso o afán de comunicación de esa verdad a los demás.

Éste es el punto en donde que hay que coger al filósofo y preguntar: ¿’Por qué el afán de comunicación de la verdad filosófica y de la reducción de esa verdad plural a una verdad unitaria?

Y aquí es donde yo creo que se ve que no se trata, en modo alguno, de un afán de saber por saber. Se trata, sencillamente, de un afán de superioridad, de dominación por el saber. No se trata de comunicar la propia visión, la visión que se obtiene del lugar ${ }^{17}$ metafísico que uno ocupa en la realidad universal; no se trata de comunicarla por pura afición — por decirlo así—; se trata de comunicarla por afanes de imposición.

Pero esta es una tesis que ha de ser demostrada y la demostración tiene que ser doble. Por una parte, tiene que fundarse en un análisis de la historia íntima del filósofo y, por otra parte, tiene que fundarse en un análisis de la contextura misma del filósofo, de la realidad y de la vida filosófica. Yo creo poder suministrar ambas pruebas.

La Filosofía, desde sus orígenes mismos, es, como dije antes, el saber del principio. No es nada banal, en términos técnicos, el definir la Filosofía desde los primeros fundamentos, tanto que de ella nosotros podremos sacar este término del ......... El primer fragmento de la Filosofía que se conserva, el fundamento de ......... ya trata, con un carácter técnico normativo, del puro afán que a todos es común. Y en el texto cumbre de la Filosofía antigua nos encontramos exactamente con la misma definición de la Filosofía, como la Ciencia del principio, como la Ciencia principal, con un sentido de prosopopeya y con expresiones tan claras y relevantes como las de que "el filósofo está llamado a mandar y a ser obedecido por los menos sabios que él, etcétera, etcétera”.

Pero esta prueba no es la que puede interesar ni ser suministrada en una conferencia. Lo verdaderamente interesante aquí y lo único practicable aquí es el acto que se expresa en el análisis del contenido mismo de la Filosofía o en el análisis, por otra parte, de este afán de superioridad, de dominación por el saber, a que me acabo de referir. Afán de superioridad y de dominación es de soberbios. El saber del filósofo, según esto, estaría no en el afán de saber y de contemplar, sino en la soberbia por el afán de superioridad y de dominación.

${ }^{17}$ Corregimos el indudable error del original, que aquí dice "logos". 
El filósofo sería un soberbio. Aquí tendríamos que ver lo que, en términos de técnica filosófica, se llamaría una fenomenología del bien. ${ }^{18}$

Estas observaciones las he hecho en compañía de mis discípulos y especialmente en Barcelona, en compañía de unos amigos, y hemos observado el vocablo "soberbio" etimológicamente y encontramos que es una palabra que deriva de "ser superior". Y hemos analizado la soberbia analizando el aspecto del hombre soberbio desde sus signos externos, como, por ejemplo, su mirar, y hemos encontrado que la mirada del soberbio puede ser definida o está definida por frases vulgares, como: "Lo miró de arriba abajo", "Lo miró de pies a cabeza". Y hemos analizado las cosas, aquellas cosas, objetos y entes no humanos a quienes se aplica la soberbia, como: una torre soberbia, una mujer soberbia. Y hemos encontrado en todos ellos unos elementos análogos que reconocen aun para el soberbio, un concepto social, un concepto de apartamiento jerárquico. Pero, por lo demás, al encontrar en el filósofo un hombre soberbio, no encontramos la soberbia, porque hay hombres mucho más soberbios que el filósofo.

¿Qué es lo que caracteriza y distingue al filósofo y al soberbio? En primer lugar, la debilidad. El filósofo es un soberbio débil, débil en este sentido. Hemos dicho que la vida consiste precisamente en la convivencia, en el trato, ocupación y preocupación con las cosas y las personas. Éste contacto puede ser directo e indirecto y entonces apreciar por qué las cosas son ásperas y las personas duras y el trato social muchas veces parezca difícil o rudo. Un hombre débil, un hombre de los que pertenezcan a la especie de los que necesitan ir con la cara alta, cuando rehúye esta concreción convivencial, se recluirá en la abstracción. Esto no llevaría consigo ninguna complicación si se tratase de un ente humilde; pero si se trata de un soberbio, un hombre dominado por el afán de ser superior y dominar a su vez a los demás, la situación es más difícil, porque, por un parte, se ve obligado a recluirse, a retirarse, a producirse en un medio perfecto $y$, por otra parte, aspira precisamente a descollar entre los demás, a regir a los demás que rigen su vida.

Aquí viene la razón y aquí está el truco de la Filosofía. Está en el logos, en la razón y en la idea. El filósofo es un soberbio débil que en lugar de acometer directamente la convivencia con sus prójimos, que en lugar de arrostrar la vida pública en cuanto tal, se recluye en su biblioteca, practica un hueco entre los libros y tira lo que él escribe, por la ventana, a la plaza pública. Es el hombre que presentándose como el hombre que enseña a regir y a dominar a los demás, les lanza las ideas por medio de las cuales pretende dominarlos o regirlos, sin directa responsabilidad, sin ir a la plaza pública y prefiere esconderse este

\footnotetext{
${ }^{18}$ Sería más coherente con el contexto que aquí se tratara de "una fenomenología del soberbio" (o "de la soberbia").
} 
principio o idea sin asumir la responsabilidad que se deriva de este gesto y de esta gestión.

Y esto yo creo que ya pasa con el primer filósofo, de quien nos quedan obras en cantidad bastante para podernos hacer una idea precisa de lo que en realidad fuera Heráclito, porque los unitarios ${ }^{19}$ antiguos nos presentan a Heráclito como un filósofo que renunció a la diadema de su ciudad natal, que vivía en un apartado lugar de su ciudad y no disimula sus inclinaciones en el poco trato que tiene con los demás. Pero Heráclito es el primero que escribe un libro, el Logos y las palabras contenidas en aquel libro son precisamente "las que todos debéis oír y debéis imitar". La primera parte del libro es cosmológica, pero la tercera es un tratado de política.

Y entonces la Filosofía, interpretada así, no haría más que corroborar esta tesis.

La mejor de las filosofías modernas, en Kant, se presenta con los mismos caracteres históricos. Mi maestro Ortega llama a Descartes "el genio del prescindir". El propio ........ le sirve de intermediario y, al mismo tiempo, de muro de contención. Pero Descartes tiene que escribir muchos discursos y muchos libros para justificarse de que pretende ${ }^{20}$ reformar el imperio en la vida pública y en la sociedad, prueba de que su conciencia le acusa de intento tal.

El filósofo es, pues, un soberbio constitutivamente débil, pero que tiene la posibilidad de utilizar la razón, la idea, el logos o la palabra y, parapetado detrás de ella y por medio de ella, esquivar el esfuerzo directo de la vida pública, de dominar, sencillamente, por el poder de la razón. Y esta interpretación, si fuese cierta, explicaría una enorme cantidad de cosas inexplicables hasta ahora.

Si ustedes recuerdan lo que he dicho hace unos momentos, sobre la adolescencia y la madurez de la vida, entonces comprenderán hasta qué punto no es viable el admitir tampoco lo que de la Filosofía nos han dejado los griegos y que Platón resume en pocas líneas, algo más allá de lo que leí como introducción de la conferencia primera, diciendo que "El filósofo es un viejo que anda cuchicheando por los rincones de Atenas, con una banda ${ }^{21}$ de mozalbetes. Hace cosas de niño y cosas de viejo, cosas de la juventud y de la senectud, pero no cosas serias y propias de la madurez". Tiene razón cuando dice que "el hombre que haga filosofía en la madurez, merece una buena tanda de palos, porque es el hombre que se sustrae a las responsabilidades sin pretender sustraerse íntegramente a las exigencias de esa misma vida, puesto que aspira a regir y a dominar y, en el fondo, es un político, pero no quiere comparecer

\footnotetext{
${ }^{19}$ Parece claro que esta palabra del original no hace sentido. Quizá Gaos escribió "historiadores" (¿o "anecdotarios"?).

${ }^{20}$ Quizá la transcripción debió escribir aquí "de que no pretende".

${ }^{21}$ En el original, "tanda"; también podría ser "panda".
} 
en el ágora o en la plaza pública”. Y, por fin, sólo una interpretación así, nos permitiría comprender la última esencia de la Filosofía del filósofo como inhumanidad.

El hombre necesita comparecer en función de ente y no más. Yo no digo que Dios exista sólo por esto, pero pudiera ser. Y, desde luego, me inclino a pensar que debiera existir en principio para esto.

Ahora bien, los filósofos también, desde siempre, han creído que la Filosofía era aproximación a lo divino, participación de Dios o beatificación. Aristóteles dice en esa página suprema, que "el filósofo participa en la contemplación de lo que constituye la vida misma de Dios, que es la vida contemplativa." Hegel y otros filósofos, fuera de sí mismos, creen que se ha acabado la historia del pensamiento.

Pues bien, yo no. Yo creo que esta es la última y decisiva hipocresía del filósofo. El filósofo no es beatífico ni participa de la vida divina, sino que es todo lo contrario, es demoníaco o satánico, de Satán; el filósofo es un ente que oscila entre el pobre diablo y Satán. Porque, en efecto, para entender al filósofo, muchos filósofos han hecho una Teología. Es posible que lo que haya que hacer es una Demonología. La más elemental exploración ya nos puede suministrar cosas muy buenas.

Yo he realizado, también recientemente, estas cosas elementales y entonces se ve que la prosopopeya del filósofo, podría ser expuesta bajo el título clásico de los nombres del demonio, porque no son los mismos y cada uno de ellos da un aspecto o sugiere un aspecto de esta personalidad.

En primer lugar, tenemos los diablos. De los diablos se habla en plural y la idea de diablo todavía no es muy seria y es bastante divertida. Sugiere algo de burlesco. Se dice: "Un humor de mil diablos", "Mi chico es de la piel del diablo, algo endiablado". No es una cosa todavía concreta. Pero hay una cierta idea de vertiginosidad y de actividad.

El demonio todavía sigue siendo pueril, pero el endemoniado es una cosa más seria que un endiablado, porque es cierto que se puede decir endemoniado al endiablado, pero no lo contrario. El endemoniado nos pone definitivamente serios; ya no se puede bromear.

En esta idea de lo demoníaco hay una idea de obstinación, de cierta grandeza, de poder, de fuerza y de impulsión. Pero si pasamos a los nombres, entonces tenemos otra cosa.

El nombre de Luzbel nos sugiere la idea de inteligencia deslumbrante. Lucifer nos sugiere una inteligencia casi hipócrita. Así se dice del astuto. Pero, definitivamente, el nombre Satanás o de satánico, nos transporta a la región de la soberbia, elevada hasta la cumbre de la maldad y de la vesania. Son los atributos del filósofo: inteligencia y soberbia. Y sólo por medio de ellas y a través 
de ellas, se puede dominar. Y cuando el filósofo no tiene más que soberbia y no tiene la inteligencia, es el pobre diablo a que me refería antes.

$Y$ vemos que las iglesias católicas han tenido siempre el sentimiento profundo de que el filósofo era un hombre soberbio que pertenece a la especie de los que tiran la piedra y esconden la mano. El vulgo ha pintado al filósofo con suspicacia y con rencor. Mas no porque no esté bien el afán de superioridad y de dominación, sino porque sólo está bien cuando se asume con plena responsabilidad.

Esto quiere decir, en suma, que el filósofo es un ente peligroso, al que hay que señalar en su hipocresía, como lo fundamental. Es menester una depuración o purificación de la vida intelectual que ponga a cada uno en el puesto que le corresponda, con arreglo a lo que efectiva, y no hipócritamente, pretende ser. Sólo estableciendo líneas puras y precisas entre el puro teorético contemplador y el científico realmente imbuido del afán puro de saber — supongamos que son los científicos positivos- y entre quienes se disfrazan de hombres teoréticos llevando en su fondo un hombre de poder, como pasa a los filósofos que de hecho han sido en el mundo, en un noventa por ciento. Sólo así se puede introducir la adecuada relación, el orden debido y la normalidad fecunda en la vida intelectual.

Pero diciendo esto yo, con toda la modestia de no ser más que un Profesor de Filosofía de una Universidad espańola, creo que perpetúo el gesto que un grupo de filósofos tuvo en la antigüedad.

La sofística no se puede entender, a mi juicio, en la Historia de la Filosofía antigua griega, si no se la interpreta como aquel grupo de filósofos que, siendo conscientes primero del verdadero ser de la Filosofía y de su constitutiva hipocresía, se decidieron a salir a la plaza pública a decir la verdad, en una palabra, a tirar de la manta y poner al descubierto al filósofo. Y por eso se armó el escándalo que se armó, porque los hipócritas que representan la Filosofía en el sentido tradicional, al ser descubiertos en su intimidad hipócrita, se rasgaron las vestiduras, como pasa siempre que alguien infringe el secreto de una comunidad.

Yo aquí he venido, evidentemente, a hacer de sofista y, por lo tanto, sé también cuál es el destino que por mi modestia, si queréis, me espera. Es el mismo destino que tuvieron los sofistas. El sofista ha acabado por ser, en la Historia, tomado por una mala persona, gracias a que la partida, históricamente, la ganaron los filósofos.

Yo creo que seré - y conste que no diré, por darme importancia, que seré perseguido o denostado- pero sí, por lo menos, que seré criticado, puesto que me presento como animado exclusivamente por el más puro y desinteresado de los amores al saber y al prójimo.

Y nada más. 